Floret Test, Numerical Simulations of the Dent, Comparison with Experiments

A. Lefrançois, J. Cutting, F. Gagliardi, C. Tarver, T. Tran

February 17, 2006 
This document was prepared as an account of work sponsored by an agency of the United States Government. Neither the United States Government nor the University of California nor any of their employees, makes any warranty, express or implied, or assumes any legal liability or responsibility for the accuracy, completeness, or usefulness of any information, apparatus, product, or process disclosed, or represents that its use would not infringe privately owned rights. Reference herein to any specific commercial product, process, or service by trade name, trademark, manufacturer, or otherwise, does not necessarily constitute or imply its endorsement, recommendation, or favoring by the United States Government or the University of California. The views and opinions of authors expressed herein do not necessarily state or reflect those of the United States Government or the University of California, and shall not be used for advertising or product endorsement purposes.

This work was performed under the auspices of the U.S. Department of Energy by University of California, Lawrence Livermore National Laboratory under Contract W-7405-Eng-48. 


\title{
FLORET TEST, NUMERICAL SIMULATIONS OF THE DENT, COMPARISON WITH EXPERIMENTS
}

\author{
A.Lefrancois (*), J.Cutting, F.Gagliardi, C.Tarver, T.Tran \\ Energetic Materials Center, Lawrence Livermore National Laboratory, Livermore, \\ CA 94550 - USA \\ ${ }^{(*)}$ Participating guest at LLNL from DGA/Centre d'etudes de Gramat - France
}

The Floret test has been developed as a screening test to study the performance

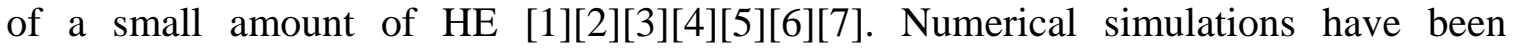
performed recently using CTH [5][6].

The objective of this study is to perform numerical simulations in order to better understand the shock waves interactions, involved in the dent formation. Different 3D wedge configurations have been tested using the Ignition and Growth reactive flow model for the HE receptor with Ls-Dyna [8][9].

\subsection{CONFIGURATION OF THE NUMERICAL SIMULATIONS}

The differences between the numerical and experimental configurations are explained Figure 2.

The reduced numerical configuration has only a radius of $10 \mathrm{~mm}$ and a copper thickness of $6 \mathrm{~mm}$, with non -reflective boundaries (the shock front doesn't reflect when it reaches the boundary). The reduced numerical configuration does not take into account the release wave from the side, top and bottom of the steel and copper confinement.

The large numerical configuration has the same radius as the experimental configuration, but does not model the entire steel plates below the copper and on top of the set-up. The large numerical configuration takes into account the release wave front the side, but not the one from the top and bottom of the experimental set-up. 
3D wedge configurations have been used with a ALE (Arbitrary Lagrangian Eulerian) description and a resolution no less than 24 elements/mm, because of the small thickness of the aluminum flyer.

Many parameters have been investigated to study the velocity of the aluminum plate and the dent in copper :

- The influence of the initiation (point, or plane) of the HE donor

- Different inert or HE receptor have been tested : teflon, UFTATB, LLM105

\subsection{MODELS DESCRIPTIONS}

A Jones-Wilkins-Lee (JWL) equation of state has been used for the reaction products of the donor LX 16 composition. The donor charge is point-initiated at the bottom axis or flat initiated within the flyer diameter of the slapper detonator.

The Ignition and Growth reactive flow model has been chosen for the HE receptors [8][9][10].

For the Aluminum flyer, the steel confinement and the copper plate, classical Gruneisen equations of state have been applied. For the steel confinement and the copper plate, Johnson-Cook constitutive law has been also applied to follow the dent formation [11]. 


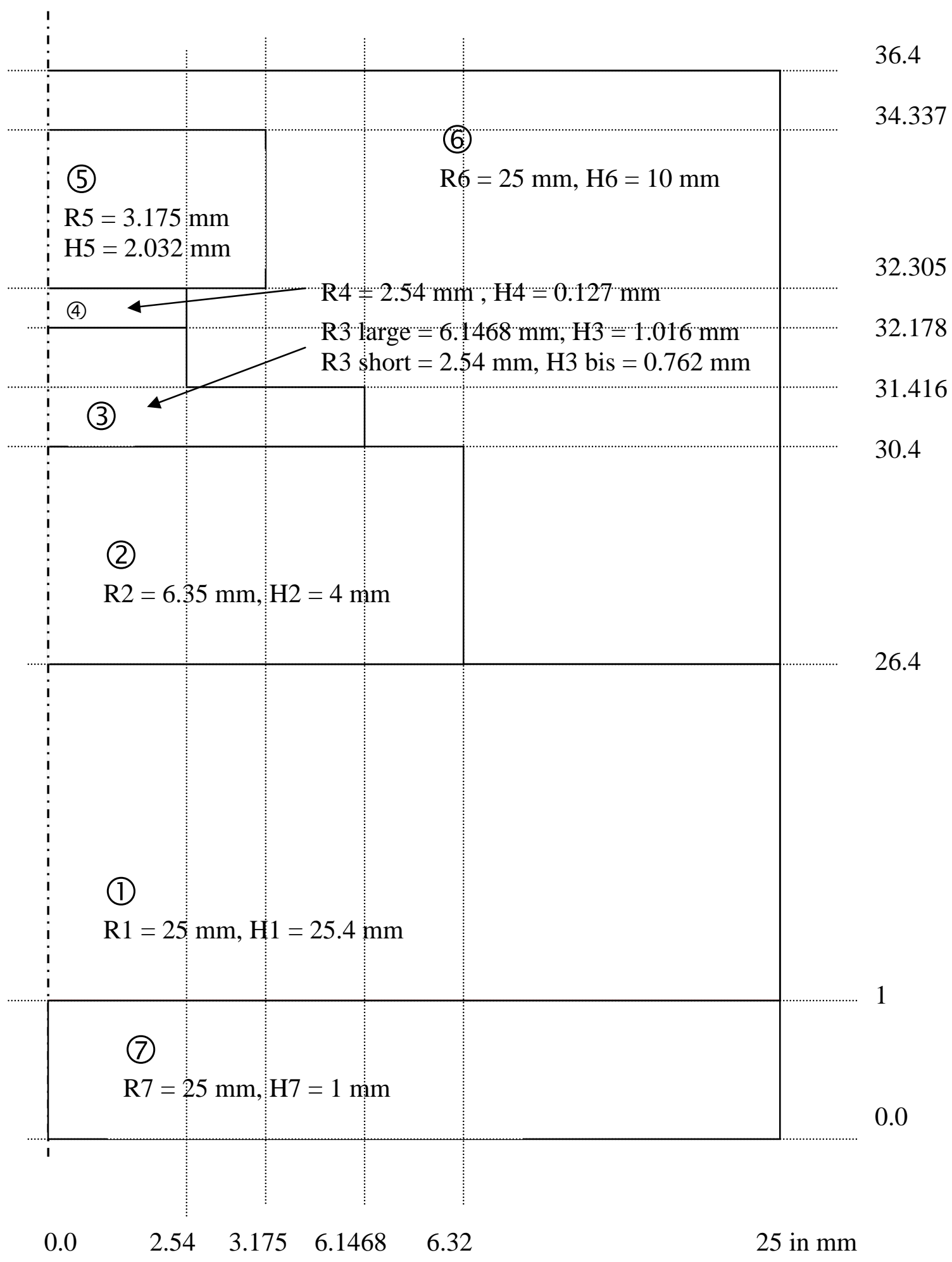

Figure 1 : large numerical configuration of the Floret test (1-Copper,2-HE receptor, 3-Air, 4-Al flyer, 5-HE Donor, 6-Steel, 7-Steel), for the reduced configuration the radius is $10 \mathrm{~mm}$, for the experimental set-up the height of 7 is 1 inch thick 


\section{$1.3 \quad$ NUMERICAL SIMULATION RESULTS}

\subsubsection{Aluminum flyer free surface velocity}

The numerical results for the Aluminum flyer free surface velocity and curvature are presented Figure 2 and Figure 3. The final velocity is retrieved within $4 \%$ using the flat ignition of the LX16 pellet with the slapper radius of $0.33 \mathrm{~mm}$. The front velocity is higher for the flat ignition than the point ignition simulation and than the experiments [7][12]. The experimental jump off reference [12] seems to be lower than numerical values, more than $30 \%$, compared to the point initiation. But the point initiation calculation retrieve the experimental jump off reference [7].

The sweeping rate of the frame camera could differ between the two experimental results; the thickness of the pellet is $16.7 \%$ higher for the reference [7]. Therefore, the steady state has been obtained in this case. For the calculation, a beta burn model has been used with a steady detonation, unable to reproduce the ignition and growth processes for short thicknesses.

Nevertheless, the final free surface velocity is reproduced with a good accuracy, which allows us to analyze further the second stage of the Floret test.

\subsubsection{Second stage with Teflon}

The comparison of the numerical simulations with experiment is presented Figure 4.

The reduced numerical configuration gives a similar dent as the experimental one after 13.5 microseconds after the initiation of the first stage. The motion of the dent does not stop in this configuration due to the side release waves, because of the applied non-reflective boundaries in order to reduce the mesh size.

The simulation has reached 17.1 microseconds with the large configuration, and overdrive the experimental dent. The release wave from the side of the steel plate, taken into account in the large configuration, is not sufficient to stop the dent motion.

Further analysis is needed to take into account the release wave from the bottom of the steel plate below the copper, in order to be able to stop the dent formation.

\subsubsection{Second stage with UFTATB}

The comparison of the numerical simulations with experiment is presented Figure 5. Only the reduced configuration is computed here. The side release from the confinement is not taken into account. 
The experimental dent is not reproduced even 12.5 microseconds after the initiation of the first stage. The experimental depth is reached on the axis, but not the side dent.

A strong effect of the re-shock due to the steel confinement has been noticed and drives the motion of the copper near the axis. A teflon confinement instead of steel should reduce the confinement effect on the dent itself.

Dead zones are identified by calculation in the top corner of the pellet, see Figure 6. But, there is a shock desensitization issue, which is very difficult to reproduce there, see Figure 7.

Further analysis is needed with a higher mesh resolution in order to retrieve the real curvature of the detonation wave and the confinement effects, which should influence directly the dent formation.

\subsubsection{Second stage with LLM105}

Further work is needed to identify the Ignition and Growth parameters for LLM105; the actual parameters work only for sustained SDT process at low impact pressure [8]. 


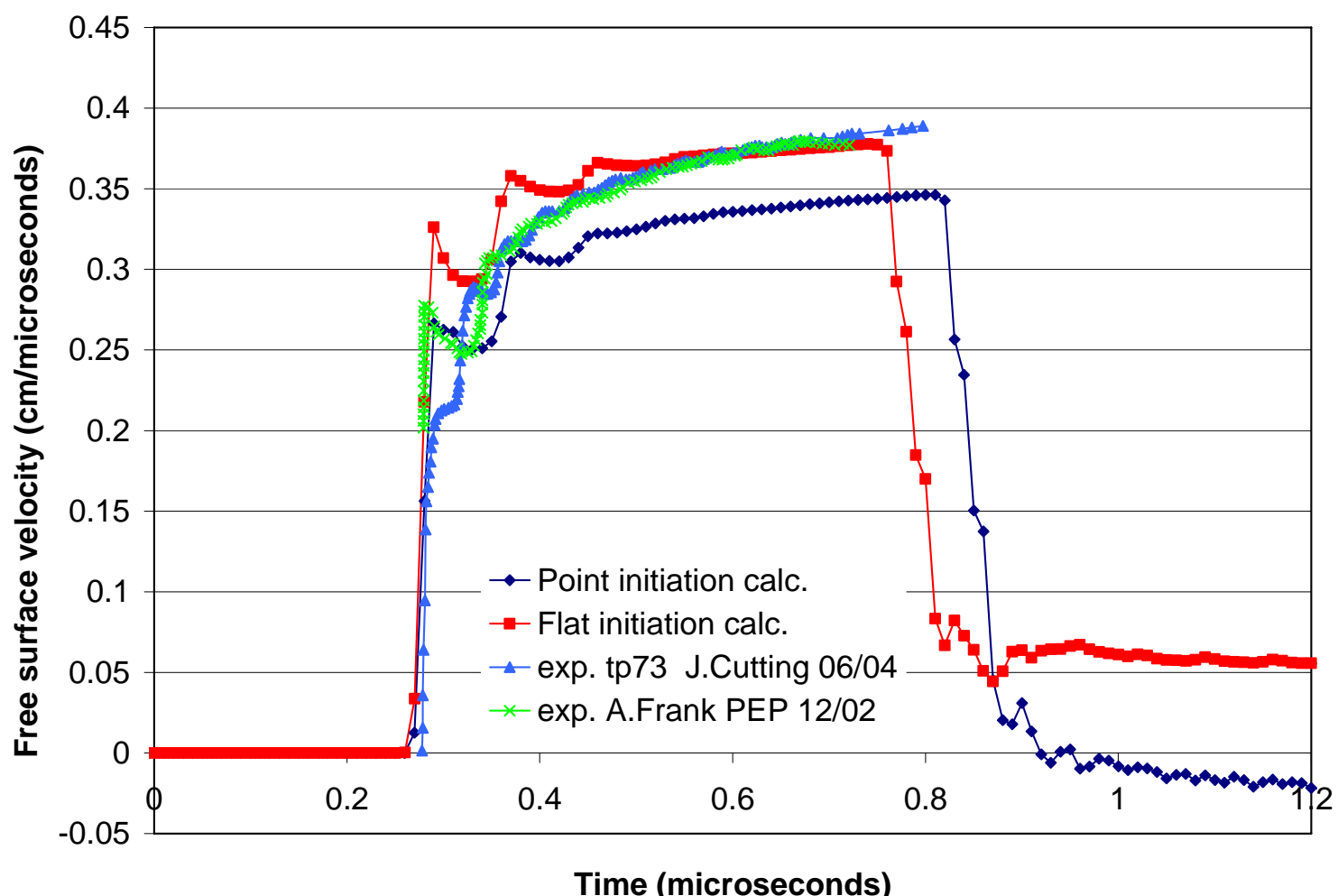

Figure 2 : Free surface velocities of the Al flyer, point ignition in green, flat initiation (slapper radius $0.33 \mathrm{~mm}$ ) of the LX16 pellet

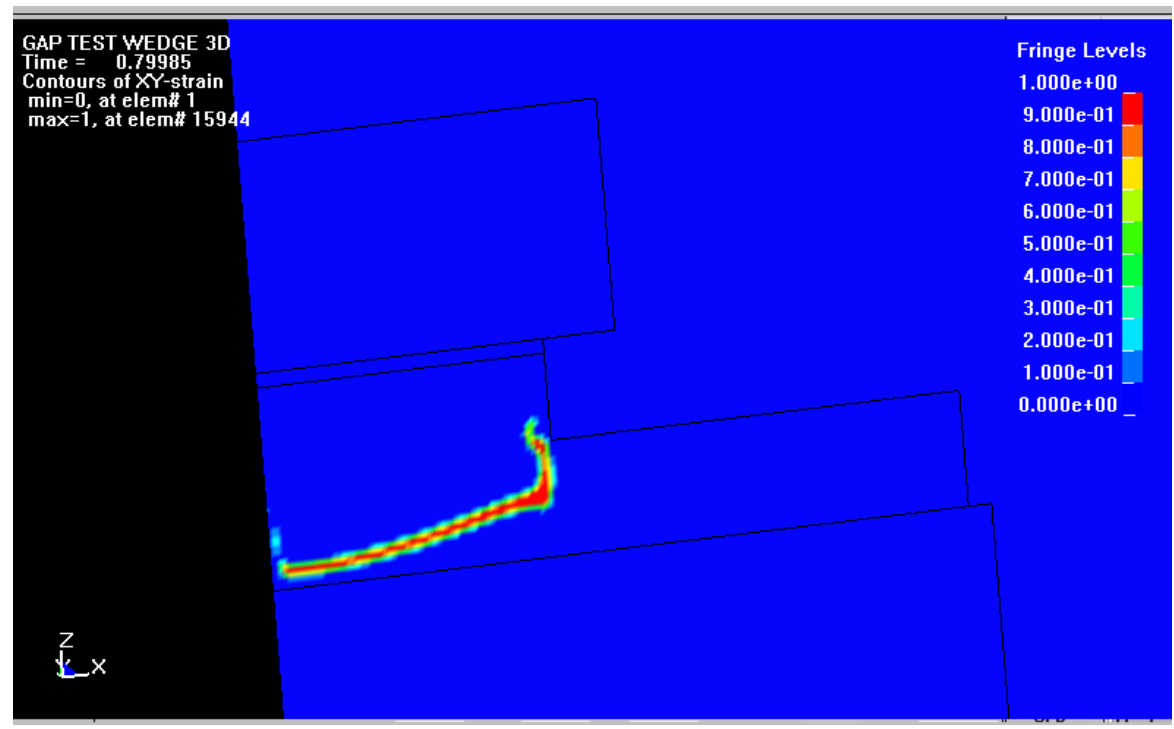

Figure 3 : Tiny plate curvature, wedge issue on the axis for the ALE description 


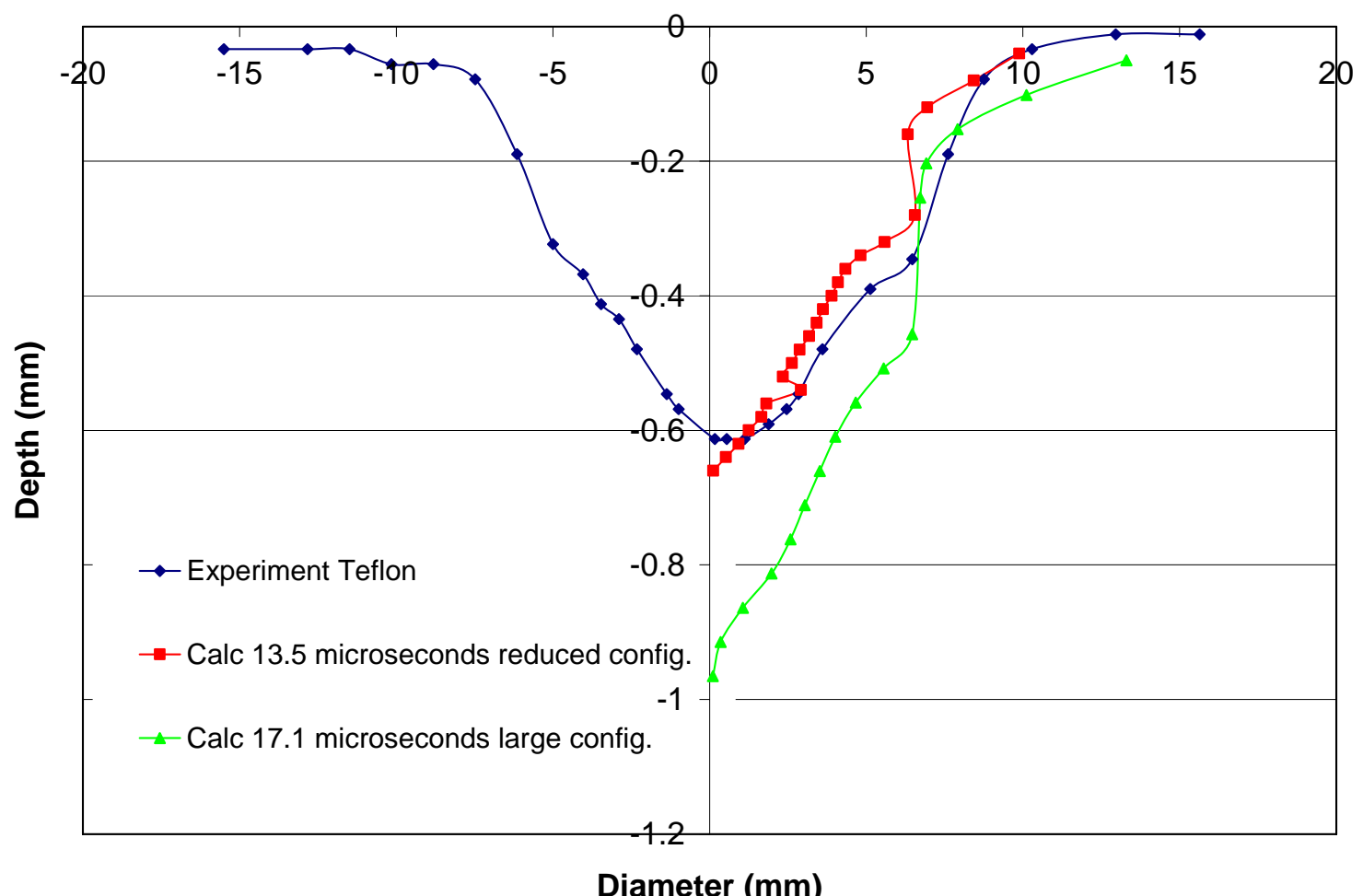

Figure 4 : Dent in Copper for a Teflon second stage

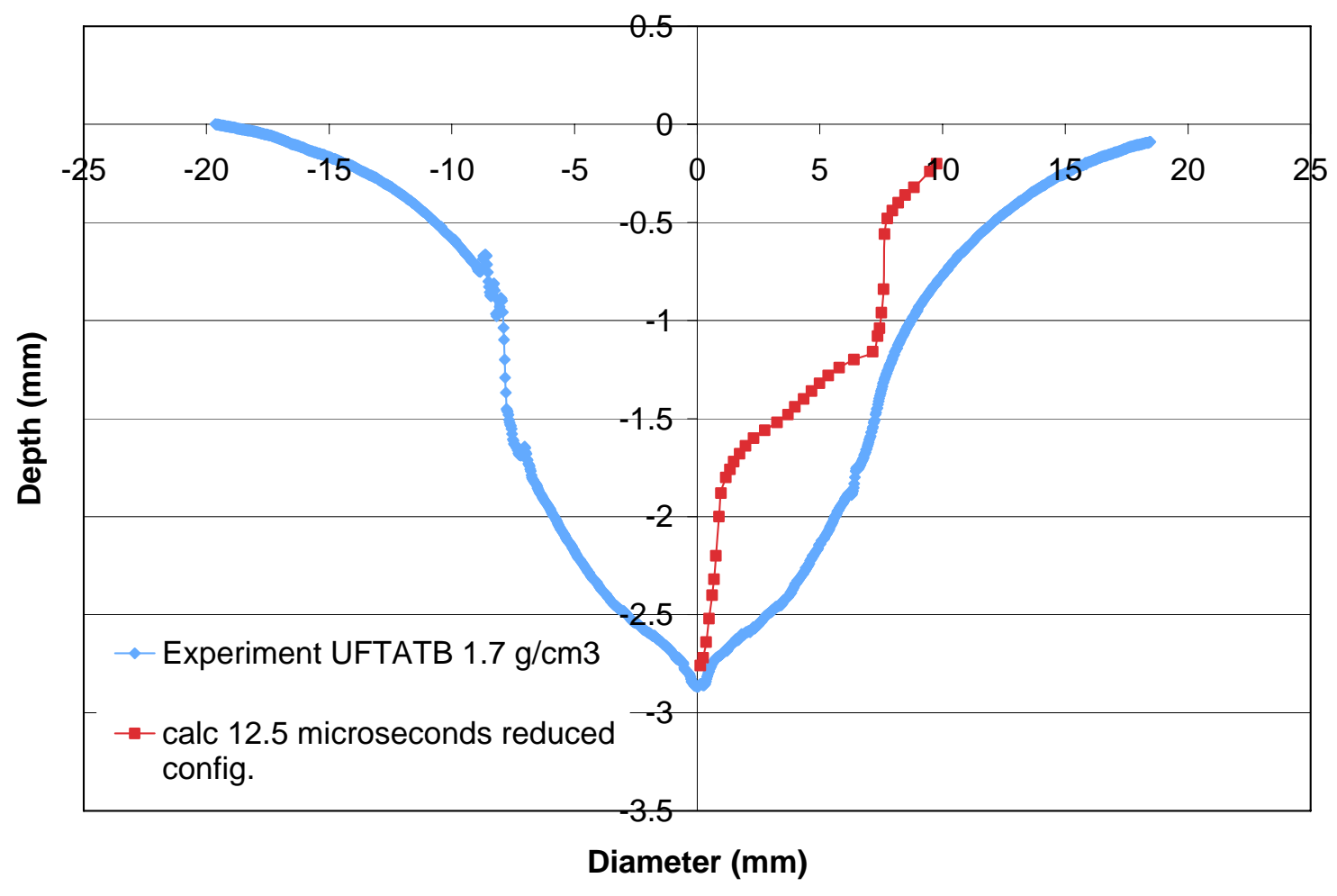

Figure 5 : Dent in Copper for a UFTATB second stage 


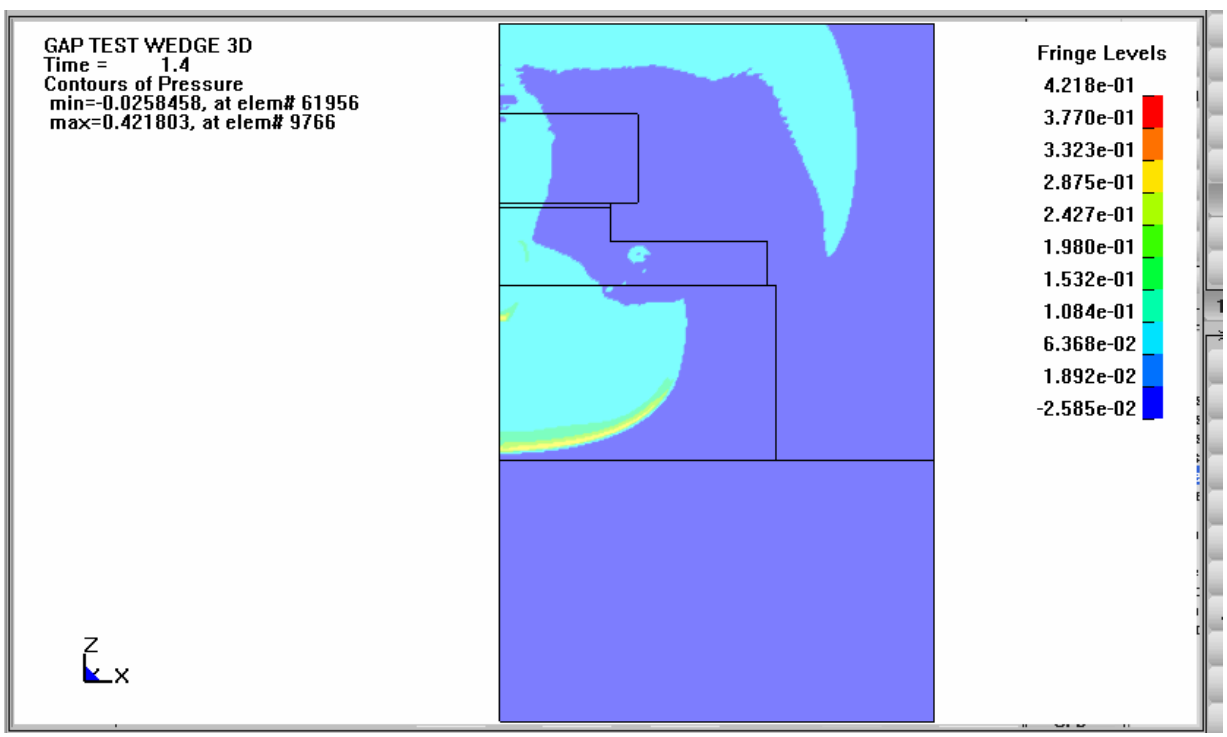

Figure 6 : UFTATB reduced configuration, dead zone on the top corner

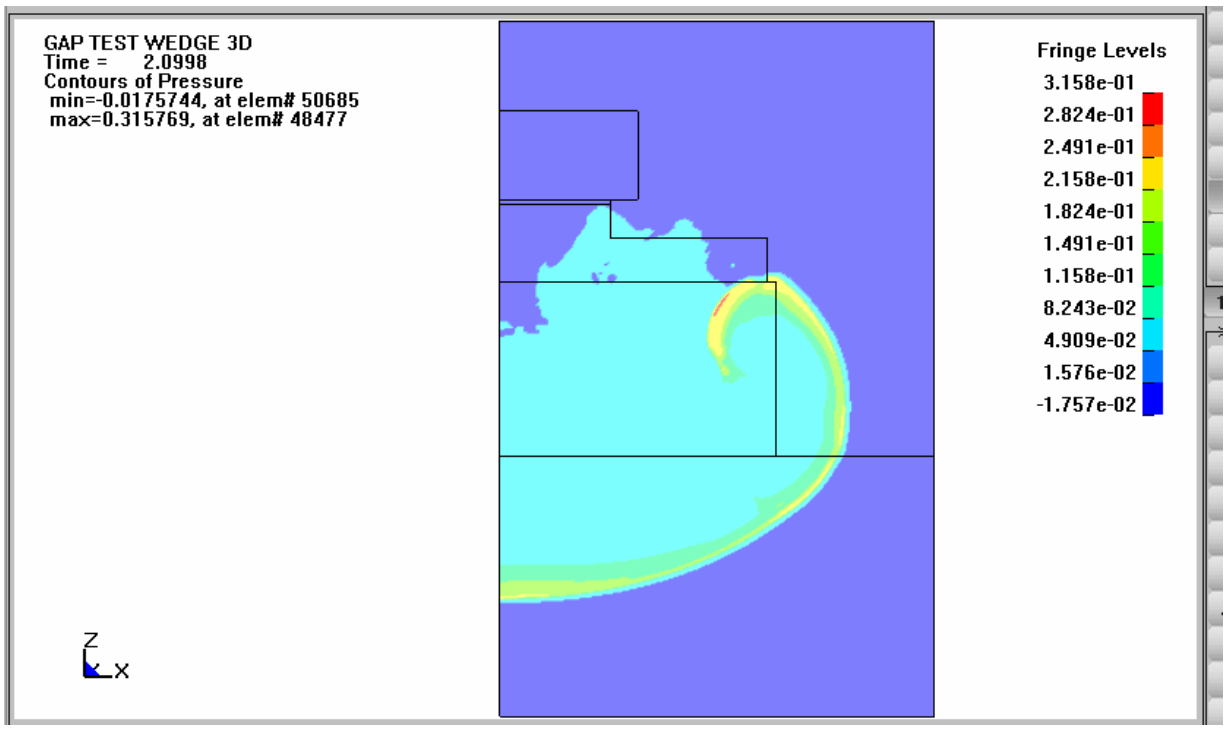

Figure 7 : Re-detonation on the top corner due to the strong reflection with the steel confinement, Here is the shock desensitization issue, reduced configuration

* This Work has been performed under the auspices of the U.S. Department of Energy by the Lawrence Livermore National Laboratory under Contract W-7405-Eng-48

\section{References}

[1] J.L.Cutting, H.H.Chau, R.L.Hodgin, D.M.Hoffman, F.Garcia, R.S.Lee, Estella McGuire, A.R.Mitchell, P.F.Pagaria, R.D.Scmidt, R.L.Simpson, P.C.Souers, 
R.W.Swansiger, A Small-Scale Screening Test For HE Performance : Application to the New Explosive LLM-105, LLNL, 11th International Detonation Symposium, Août 1998

[2] T.D.Tran, P.F.Pagoria, D.M.Hoffman, B.Cunningham, R.L.Simpson, R.S.Lee and J.L.Cutting, Small-scale Safety and Performance Characterization of New Plastic Bonded Explosives Containing LLM-105, 12th International Detonation Symposium, Août 2002

[3] J.Cutting, R.S.Lee, R.L.Hodgin, Initiation Studies, Technical Progress Review Meeting, December 1998

[4] F.J.Gagliardi, R.D.Chambers, T.D.Tran, Small-Scale Performance Testing for Studying New Explosives, $6^{\text {th }}$ VACETS Technical International Conference, June 05

[5] K.Y.Lee, J.E.Kennedy, L.G.Hill, T.Spontarelli, J.R.Stine, G.I.Kerley, Synthesis, Detonation Spreading and Reaction Rate Modeling of Fine TATB, $11^{\text {th }}$ International Detonation Smposium 1998

[6] J.E.Kennedy, E.S.Martin, N.J.Burnside, K.A.Thomas, K.Y.Lee, M.E.Martinez, I.A.Garcia, C.S.Lester, I.Plaskin, J.Campos, R.Mendes, J.Direito, J.Ribeiro, Detonation Spreading Measurement Techniques for instrumented Floret Tests, High Dynamic Pressures 2003, Saint Malo

[7] A.Frank, H.Chau, R.Lee, P.Vitello, P.C.Souers, Reaction Zone in Ultrafine TATB, Propellants, Explosives, Pyrotechnics, December 2002

[8] C.M.Tarver, P.A.Urtiew, T.D.Tran, Sensitivity of 2, 6-Diamino-3,5Dinitropyrazine-1-Oxide, J.Energetic Materials 23, 183 (2005)

[9] C.M.Tarver, Ignition and Growth Modeling of LX17 Hockey Puck Experiments, Propellants, Explosives, Pyrotechnics 30 (2005), Number 2

[10] P.C.Souers, H.G.Anderski, C.F.Cook III, R.Garza, R.Pastrone, D.Phillips, F.Roeske, P.Vitello, D.Molitoris, Lx-17 Corner-Turning, Propellants, Explosives, Pyrotechnics, 29 (2004), Number 6

[11] G.R.Johnson, W.H.Cook, Fracture Characteristics of Three Metals Sbjected to Various Strains, Strain Rates, Temperatures and Pressures, Engineering Fracture Mechanics Vol.21No.1,pp.31-48,1985

[12] J.Cutting et al., Shot TP73, LLNL, 06/15/04 